\title{
Nestling Development of Ring-necked Parakeets (Psittacula krameri) in a Nest Box Population
}

\author{
Michael P. Braun and Michael Wink*
}

Heidelberg University, Institute of Pharmacy and Molecular Biotechnology, Department of Biology, Im Neuenheimer Feld 364, D-69120 Heidelberg, Germany

\begin{abstract}
Chick development of a population of non-native Ring-necked Parakeets (Psittacula krameri) (RNP) has been investigated between 2006 and 2008 in Heidelberg, Germany. In parrots hatching asynchrony is common. RNP chicks are under natural selection to fledge synchronously with their siblings, as parents return less often to the nest after the first chick has fledged and remaining chicks may starve. Female nestlings apparently outperform the males by about one $\mathrm{d}$ in body mass gain, but also had higher measurements in tarsus, wing and tail growth. This was unexpected as adult males are generally larger than females. First-hatched chicks showed lowest biometrical values as compared to their younger siblings in several characters like body mass gain, bill, wing, and tail length. This feature may contribute to a synchronization of fledging in an otherwise asynchronous brood.
\end{abstract}

Keywords: Parrots, Psittaciformes, fledging synchronization, invasive species.

\section{INTRODUCTION}

The Ring-necked Parakeet (RNP) (Psittacula krameri) is the most successful introduced parrot with established populations in at least 24 countries worldwide. In Europe, first breeding occurred in 1885 in Britain, with established and growing populations since the late 1960s mainly in Britain, Belgium, the Netherlands, Germany, Spain, Italy, Greece, and France [1-3].

The RNP is a strictly herbivorous parrot and feeds on buds, flowers, shoots, seeds, and fruits. It only rears one brood per year. In the natural range in India, RNP breed in cavities of trees, where the nest often contains a layer of debris or wood dust, and in crevices of buildings [4]. RNP breed both in single pairs and in colonies with up to nine couples in one tree [5].The females occupy nests long before the $1^{\text {st }}$ egg is laid and defend their cavities against competitors, especially other female RNP. The clutch size ranges from 2-6, but mostly 3-4 eggs are laid. Only the female incubates and incubation lasts 22-24 d. Chicks hatch asynchronously as the female starts incubation as soon as the $1^{\text {st }}$ egg has been laid. The time lag between the laying of two sequent eggs is 1-2 days. Chicks fledge at an age of six to seven weeks [4, 6-9]. After leaving the nest, the chicks are still being fed by their parents, especially by the father for at least two weeks. After that time, fledglings gather in groups, while parents separate themselves from the young, and later from each other [10].

*Address correspondence to this author at the Heidelberg University, Institute of Pharmacy and Molecular Biotechnology, Department of Biology, Im Neuenheimer Feld 364, D-69120 Heidelberg, Germany;

Tel: 0049 (0) 6221 544881; Fax: 0049(0) 6221 544884;

E-mails: psittaciden@yahoo.de; Wink@uni-hd.de
Breeding performance, like clutch size and breeding period, is similar for introduced and native RNP [4, 6-9]. But a reduced hatching success has been registered in introduced RNP. However, non-native populations experience a reduced predation risk which balances the reduced hatching success [11]. The breeding period starts at earliest in February and ends in July [4, 12, Braun \& Wink in prep.]. In Europe, RNP breed mostly in tree cavities and largely avoid nest boxes [13]. Breeding of non-native RNP in buildings has been reported only from Britain, Germany, Belgium, and Japan so far [14, 15, D. Strubbe, pers. comm.]. For this study, we could establish two colonies, which almost entirely breed in nest boxes on buildings in Heidelberg, Germany (Braun and Wink, in prep.). This allowed us for the first time to record the nestling development in detail.

Hatching in birds can be either synchronous or asynchronous. Asynchronous hatching may regularly be found among parrots as females usually start incubation after laying of the first egg $[16,17]$. As a consequence nestlings which hatch last can experience a disadvantage. A decreased survival rate for last-hatched chicks could be found in some neotropical parrots $[18,19]$, while an evenly distributed mortality rate across hatching order has been reported for Australian Platycercus [20]. Hatching order in birds may have a great impact on the growth pattern and can differ considerably between age classes. In Burrowing Parrots body mass, wing length and tarsus were significantly higher in first- than in last-hatched chicks [40]. Krebs [21] stated that asymptotic mass for Crimson Rosellas was highest in middle-hatched male and first-hatched female chicks, and least in lasthatched male and middle-hatched female chicks. In Red Shining-parrots (Prosopeia tabuensis) the older chicks receive the double amount of food as compared to their 
younger siblings [42]. Older siblings have been observed to brood the younger nestlings, so a higher energy requirement in older chicks may explain this discrepancy. In Budgerigars (Melopsittacus undulatus), in which large clutch sizes and extreme hatching asynchrony occur, early-hatched young reduce their weight towards fledging and fledge early. The youngest siblings are known to beg the most, so they fledge with highest body mass. In Budgerigars, nestlings feed for themselves soon after fledging, thus the pressure of a synchronized fledging in this species is reduced [22]. A similar pattern is known from the Green-rumped Parrotlet (Forpus passerinus) in which smaller chicks of large broods were begging more often than their larger siblings and therefore received more food [43]. In some species, smaller and lasthatched nestlings suffer from the highest mortality. An increased mortality rate for the smallest chicks may be a result of hatching asynchrony. In Ouvea Horn Parakeet (Eunymphicus cornutus uvaeensis) third siblings had a higher mortality in the first week due to hatching asynchrony [18]. As little is known about the fledging synchronization in wild parrots, we wanted to test if there is any sign of fledging synchronization in RNP.

In birds, both male and female chicks may outperform the other sex during development because of differing paternal investment, begging behaviour, or hormone level. Maternal investment may favour the males (smaller sex) like in Bengalese Finch [23]. In Wandering Albatross, male chicks received more food than female chicks [24]. In Black-headed Gull female chicks (smaller sex) were begging more often than male chicks, but males (larger sex) did have a higher asymptotic body mass [25]. An artificially increased corticosterone level prior to incubation slowed the growth of male, but not that of female chicks in Japanese Quail [26]. In chicken, higher amounts of growth hormone expression were found in male than in female chicks [27]. In the dimorphic Crimson Rosella (Platycercus elegans) adult males are larger than adult females. Male chicks grew faster and were larger at fledging than females [20]. In contrast, no differences in chick development related to sex were found in the monomorphic Burrowing Parrot (Cyanoliseus patagonus), where adult sexes are of similar size [19]. RNP shows plumage dimorphism but only a slight size dimorphism [28].

The aim of this study was to document and to analyse the growth pattern of RNP chicks in a nest box population in detail, in which male and female chicks were identified by molecular sexing. It was analysed whether chicks of different sex and hatching rank develop equally and if there is any sign of fledging synchronization. This is the first time that the development of RNP chicks has been investigated in detail.

\section{MATERIALS AND METHODS}

\section{Study Colonies}

Since 1974, Psittacula krameri is resident in the RhineNeckar-Region of Germany. The first breeding in the city of Heidelberg was recorded in 1990 [1]. At some buildings, Great spotted Woodpecker (Dendrocopos major) had pecked several holes into the Styrofoam layer of thermal insulation of houses. These hollows had been enlarged by RNP so that they expand up to $1.5 \mathrm{~m}$ in length and $40-50$ litre in volume
[15]. In 2001, the first case of broods in such cavities was registered [29]. After the breeding season, nest boxes (18 x $18 \times 45 \mathrm{~cm}$, entrance diameter $5.5 \mathrm{~cm}$ ) were placed in front of both, used and non-used, cavities in house insulations, so RNP were forced to breed in nest boxes the next season. In total, 40 nest boxes were thus installed on the walls of buildings in two localities since 2004 (20 boxes per site).

\section{Catching of RNP}

During 2006 to 2008, 25 adult females and 2 adult males were caught, sampled, measured and ringed (Series UA... and later UH..., Vogelwarte Radolfzell) for this study. Adults were mainly captured in April, some also in May. Males rarely visit the nest; this is the reason why only 2 adult males could be included in the dataset. As soon as the chicks hatched in April, adult female RNP were caught at their nests and sampled. Even several nest controls did not induce the females to abandon their chicks.

\section{Sampling of Nestlings and Molecular Sexing}

150 individual chicks have been sampled, measured and ringed. Blood or feather samples (2-4 growing feathers per chick) were collected from each individual. The brachial vein was punctured with a sterile needle and about $100 \mu \mathrm{l}$ blood were collected and stored in a modified EDTA buffer [30, 31]. Samples were stored at $-20^{\circ} \mathrm{C}$ until DNA isolation. Total DNA was isolated from $100 \mu \mathrm{l}$ of blood using standard proteinase K (Merck, Darmstadt) and phenol / chloroform protocols [32]. Molecular sexing was conducted following standard protocols established in our laboratory by amplification of DNA markers on the sex chromosomes [33]. In general, separation of the PCR products by high resolution polyacrylamide electrophoresis revealed one band in males and two bands in females.

\section{Biometrics}

The following morphological parameters were measured: body mass (g), bill length $(\mathrm{mm})$, bill width $(\mathrm{mm})$, tarsus $(\mathrm{mm})$, toe span $(\mathrm{mm})$, wing length $(\mathrm{cm})$, and tail length $(\mathrm{cm})$. For the measurements standardized methods have been used following Proctor and Lynch [34]. Bill and tarsus measures were taken sliding callipers (to nearest $0.1 \mathrm{~mm}$ ) and wing and tail measures with a stiff metal ruler (to nearest $1 \mathrm{~mm}$ ).

Bill length was measured from the distal edge of the cere to the tip of the upper mandible. Bill width was determined at the base (broadest part) of the bill. Young chicks carry a fleshy skin edging on the base of the bill, which contributed to its width.

Tarsus length is considered as the distance from the middle of the intertarsal joint to the distal edge of the last complete scale before the toes begin. As young parrots have very fleshy and short legs this measurement was sometimes difficult to take. Toe span was measured to nearest $1 \mathrm{~mm}$ as the maximum distance from the tip of digit 3 to the tip of digit 4 (the two longest digits). The foot was flattened on a paper board covered with millimetre paper. At a mean age of 34.6 $( \pm 10.4)$ d chicks $(n=90)$ had a mean toe span of $46.8( \pm 2.8)$ $\mathrm{mm}$ when toes were cramped and $47.9( \pm 2.8) \mathrm{mm}$ when relaxed (corr. 0.924). The exclusion of the claw from toe 
length measurements allowed a better comparison between the values of chicks and adult parakeets because adults often have lost their claws due to heavy frost bite in temperate zone winter.
Wing length was taken with a from wrist joint at the bend of the wing to the tip of the longest primary feather (p8). The wing was softly flattened on the ruler to standardise the measurements within the groups, according to Butler [35: 214]. Before feather growth started, the wing length was de-

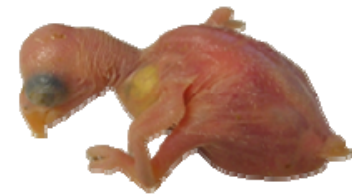

3 days

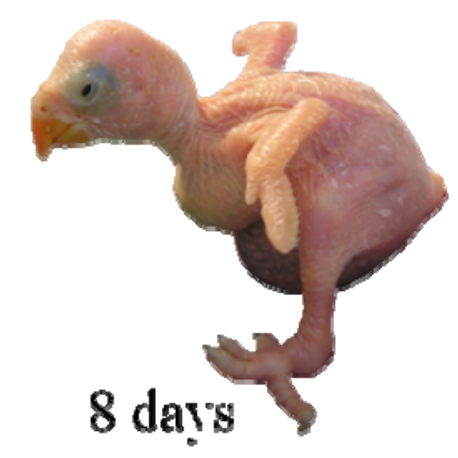

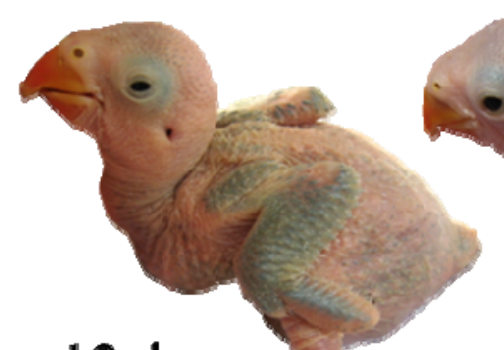

12 dars

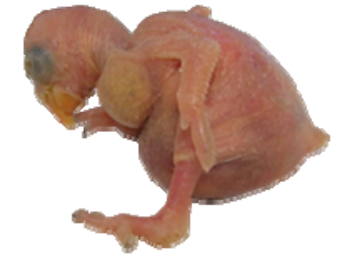

5 dars

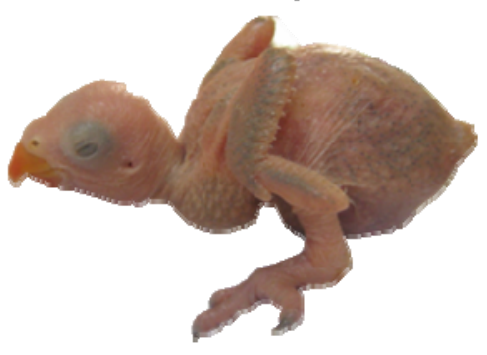

10 days
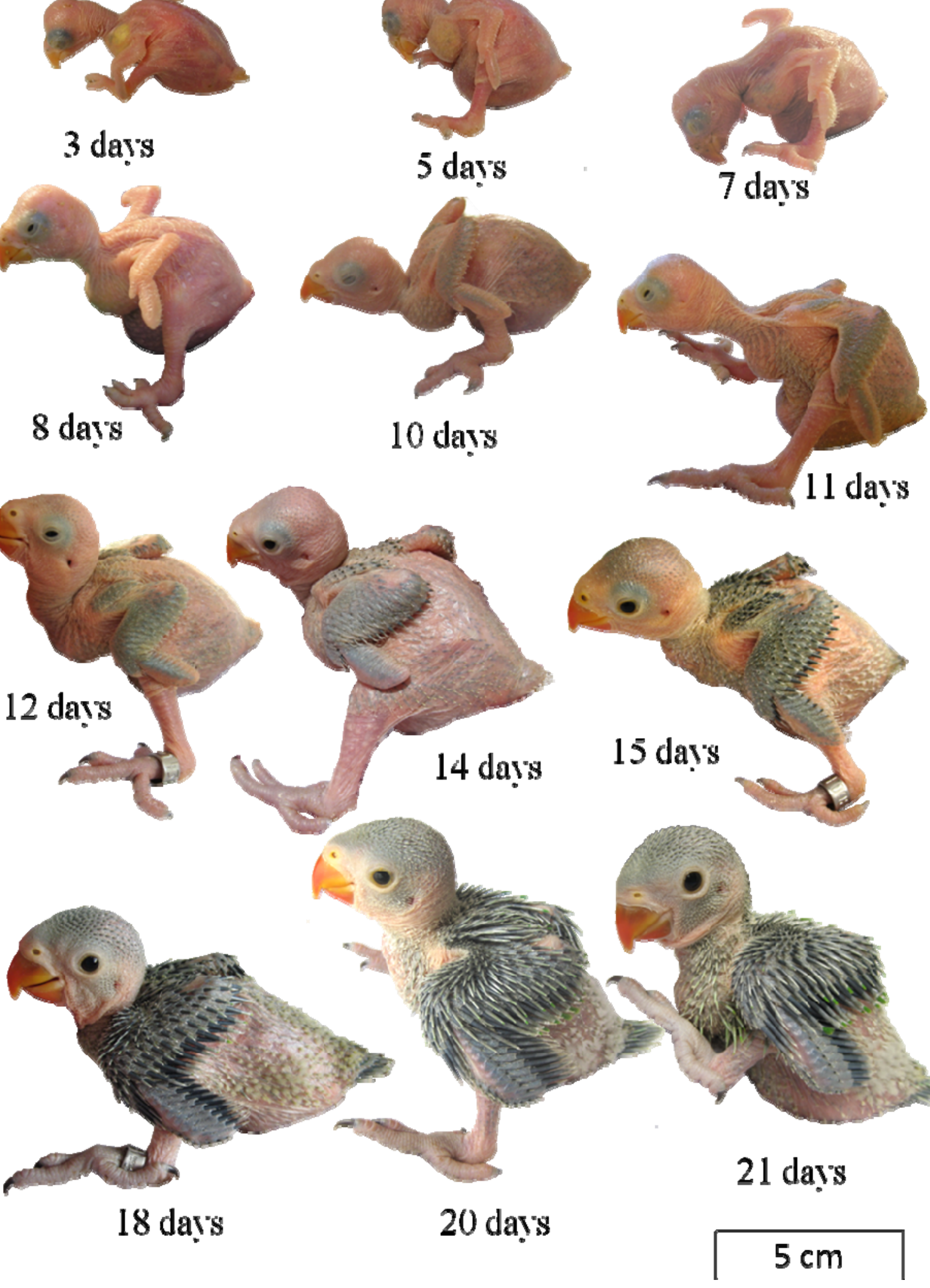
Fig. (1). Contd.....

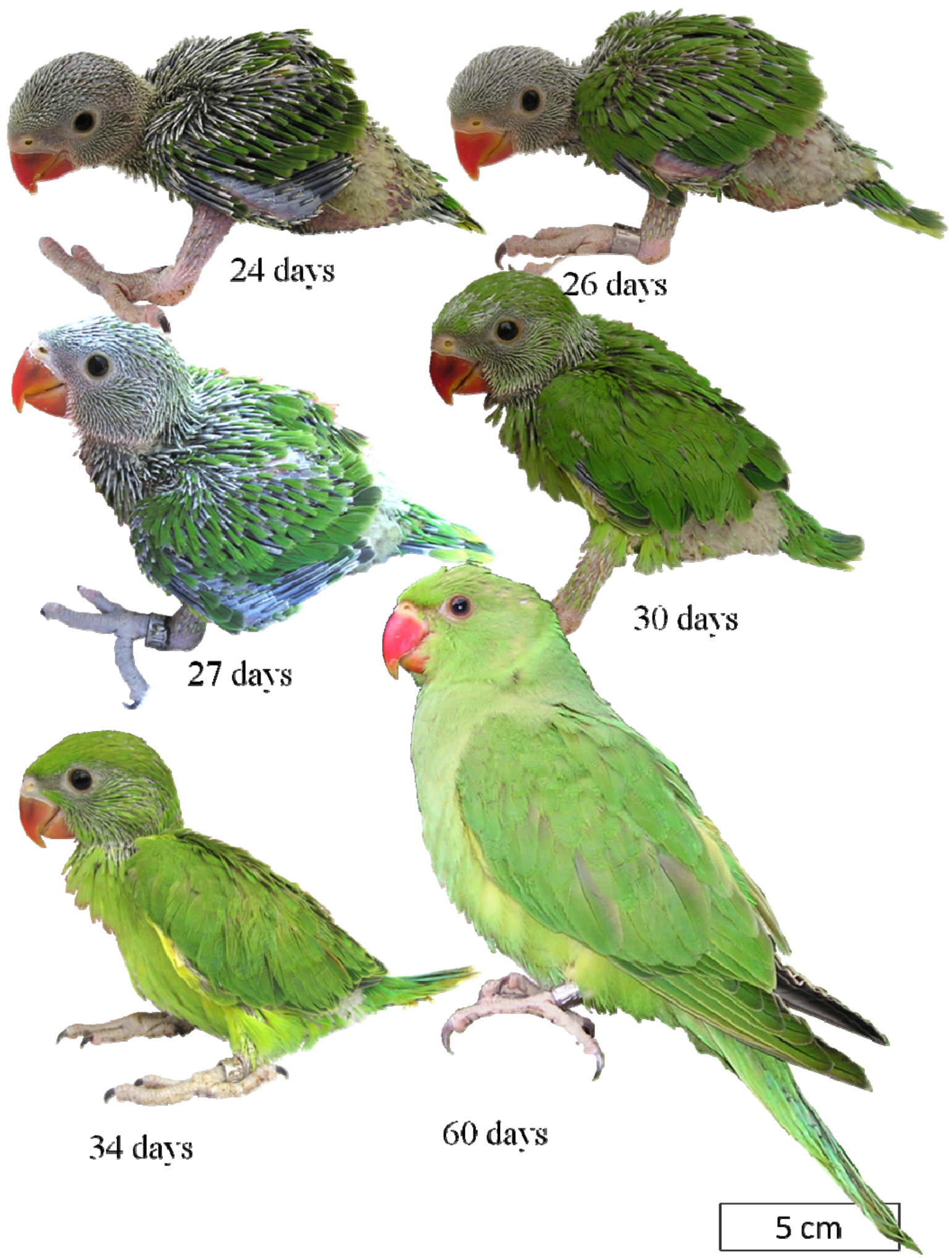

Fig. (1). Photographic documentation of chick development in Ring-necked Parakeet (3 to 60 days).

termined as the maximum length of the naked wing. For tail length measurements (length of the longest feather) the distal tip of the ruler was placed between the two central tail feathers.
Body mass was measured using two Pesola scales (100 g to the nearest $1 \mathrm{~g}$ or $300 \mathrm{~g}$ to the nearest $2 \mathrm{~g}$ ). For measurements, the birds were placed in a small cotton bag. 


\section{Fledging Age and Ageing of Chicks}

Chicks could quite easily be aged between the age of 12 and $30 \mathrm{~d}$ according to the growth status of the feathers. We compared each chick with an age table containing photographs of a captive $P$. krameri chick from 4 to $44 \mathrm{~d}$, for which photographs were taken every $2 \mathrm{~d}$ [36].

\section{Growth Stages}

According to the different shapes of growth curves, we divided nestling ages into different stages for our linear mixed-effect model which were derived from residual patterns. For better comparison (sex, hatching order) we took mean values at different stages (early, medium, late nestling phase). This distinction differed between characters, as outlined Table $\mathbf{1}$ and Table $\mathbf{2}$.

\section{Statistical Analysis}

Because many measurement data are dependent (chicks were measured several times), we used the linear mixedeffect model (lmer) of the Package lme4 in the 'R' version 2.7.2 for statistical analyses [37]. The developmental traits have been evaluated using individual and nest box as random effects in order to account for the specific pattern of dependence. The different biometrics (body mass, bill, tarsus, toe span, wing, tail) were regarded as dependent variables, while age, sex, and hatching order were used as fixed effects. Parameters have been calculated using the restricted maximum likelihood (REML) method. Models were tested using ANOVA.

\section{RESULTS}

\section{Molecular Sexing}

Nestlings ( $\mathrm{n}=149)$ and adult birds $(\mathrm{n}=27)$ could be sexed by amplification of sex chromosome specific DNA markers using blood or feather tissue as DNA source. Sex ratio of the chicks was 1:1 (74 females, 75 males).

\section{Biometrics of Nestling Development}

Development and growth of RNP nestlings is illustrated in Fig. (1). Both, sex and hatching order within a brood can influence nestling development (Table 1 and 2; Fig. 2-8).

Body mass shows a linear increase with time within the first $25 \mathrm{~d}$, and then stays at a plateau for approximately 5-10 $\mathrm{d}$ before decreasing towards fledging. The development of body mass follows a quadratic regression and can be divided into two phases, the first phase being the mass gain phase and the second phase being the mass recession phase towards the end of the nestling stage (Fig. 2). The mass recession accounts for a weight loss of $23 \%$ in females and $19 \%$ in males (Table 2). The average body mass of adults is $149.2 \pm 11.1 \mathrm{~g}$ $(n=27)$ and is nearly reached, but not exceeded during the nestling stage.

Female chicks have an advance in body mass development of $1-2 \mathrm{~d}$ in the early nestling stage compared to males, but the mass recession is also higher in this group until fledging. As a consequence female nestlings are heavier than males in the first two growth stages, whereas at fledging males are 3\% heavier than females (Table 2). Females also show higher growth rates in tarsus, wing and tail as compared to male chicks (Table 2). In first-hatched chicks only the body mass in the middle and late nestling age is higher as compared to the younger siblings. In nearly all other measurements intermediate-hatched chicks show the highest values except early bill length, which is highest for last-hatched chicks at an early nestling stage (Table $\mathbf{1}$ ).

No significant difference could be detected in the linear mixed model of the body mass development related to clutch size (ANOVA test, $p=0.802$ ), or the calendar week of hatching (ANOVA test, $\mathrm{p}=0.53$ ), indicating that there is no

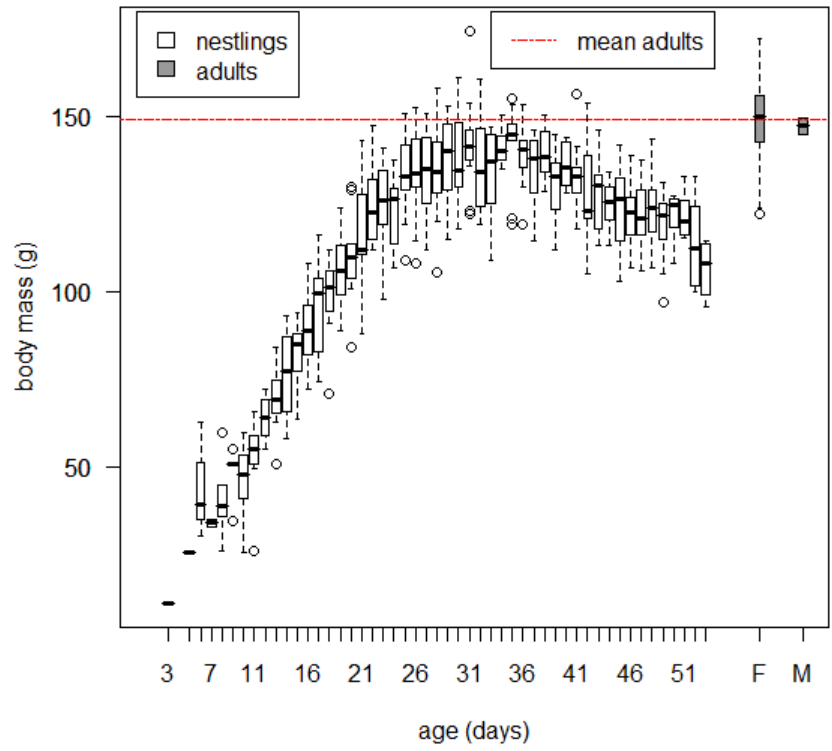

Fig. (2). Development of body mass during chick development $(n=150)$ in Ring-necked Parakeets. For comparison adult values are given with females $(\mathrm{F}, \mathrm{n}=25)$ and males $(\mathrm{M}, \mathrm{n}=2)$ on the right side, the red dashed line shows the mean value of adults. boxplot: horizontal line shows the median; the top and the bottom of the box show the $25^{\text {th }}$ and the $75^{\text {th }}$ percentiles; the vertical dashed lines ('whiskers') show either maximum value or 1.5 times the quartile range; circles indicate outliers out of the 1.5 times quartile range. 
Table 1. ANOVA Test of Morphological Features between Chicks of Different Hatching Order. P-values and Significance Level Evaluate the Role of Hatching Order Used as a Main Factor in our Linear Mixed-effect Model. Stages are Divided by Changes in Growth Curves

\begin{tabular}{|c|c|c|c|c|c|c|c|}
\hline Character & Age (Days) & 1st Hatch (Mean) & Intermediate Hatch (Mean) & Last Hatch (Mean) & $\begin{array}{c}\text { P- } \\
\text { value }\end{array}$ & Stage & $\begin{array}{c}\text { Daily Change Per } \\
\text { Stage }\end{array}$ \\
\hline \multirow[t]{3}{*}{ Body mass (g) } & 15 & 79.37 & 83.01 & 80.18 & 0.001 & $0-25$ days & 5.55 \\
\hline & 31 & 144.55 & 141.99 & 139.87 & $<0.001$ & 30-55 days & -1.23 \\
\hline & 50 & 121.21 & 118.61 & 116.45 & $<0.001$ & 30-55 days & -1.23 \\
\hline \multirow[t]{2}{*}{ Bill length (mm) } & 15 & 10.85 & 11.34 & 11.37 & $<0.001$ & 0 -30 days & 0.35 \\
\hline & 50 & 19.72 & 20.08 & 19.98 & $<0.001$ & 31-55 days & 0.18 \\
\hline \multirow[t]{2}{*}{ Bill width (mm) } & 14 & 11.03 & 11.16 & 10.99 & n.s. & $0-25$ days & 0.22 \\
\hline & 50 & 14.40 & 14.48 & 14.35 & $<0.001$ & 26-55 days & 0.10 \\
\hline \multirow[t]{3}{*}{$\begin{array}{l}\text { Tarsus length } \\
(\mathrm{mm})\end{array}$} & 14 & 16.10 & 16.18 & 15.67 & $<0.001$ & 0 -23 days & 0.35 \\
\hline & 25 & 18.20 & 18.32 & 18.00 & $<0.05$ & 24-55 days & -0.01 \\
\hline & 50 & 17.88 & 17.99 & 17.69 & $<0.001$ & 24-55 days & -0.01 \\
\hline \multirow[t]{3}{*}{ Toe span (mm) } & 14 & 35.95 & 37.89 & 36.34 & $<0.001$ & $0-23$ days & 1.48 \\
\hline & 25 & 46.01 & 46.36 & 46.03 & $<0.001$ & 24-55 days & 0.05 \\
\hline & 50 & 47.21 & 47.56 & 47.23 & $<0.001$ & 24-55 days & 0.05 \\
\hline \multirow[t]{2}{*}{ Wing (cm) } & 10 & 2.22 & 2.35 & 2.29 & n.s. & 0 -15 days & 0.19 \\
\hline & 50 & 16.53 & 16.90 & 16.81 & $<0.001$ & 16-55 days & 0.37 \\
\hline \multirow[t]{2}{*}{ Tail (cm) } & 30 & 3.98 & 4.26 & 4.23 & $<0.001$ & 18-55 days & 0.33 \\
\hline & 50 & 10.65 & 10.95 & 10.90 & $<0.001$ & 18-55 days & 0.33 \\
\hline
\end{tabular}

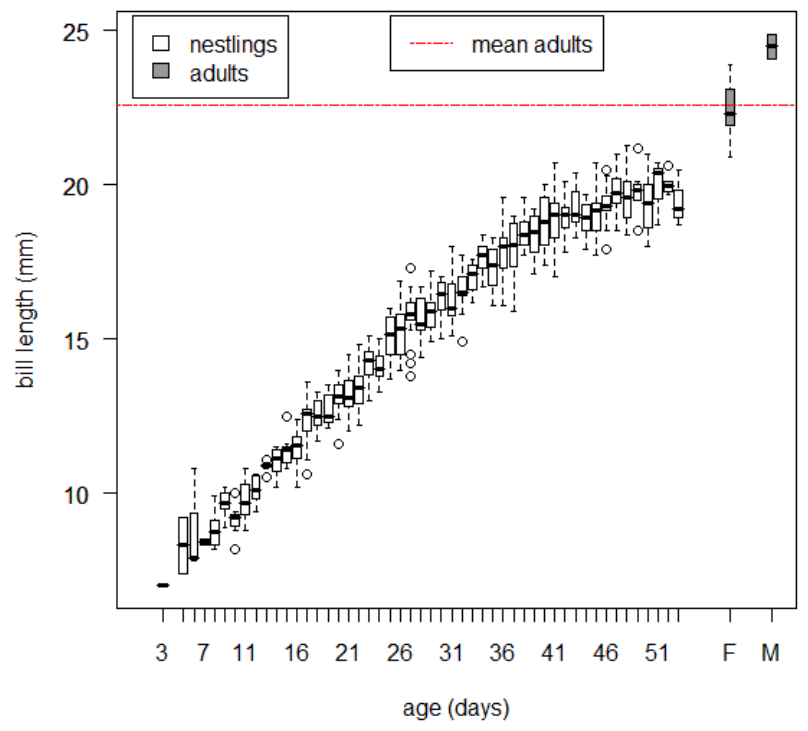

Fig. (3). Bill growth during chick development $(n=150)$. For comparison adult values are given with females $(F, n=25)$ and males $(M, n=2)$ on the right side, the red dashed line shows the mean value of adults. boxplot: horizontal line shows the median; the top and the bottom of the box show the $25^{\text {th }}$ and the $75^{\text {th }}$ percentiles; the vertical dashed lines ('whiskers') show either maximum value or 1.5 times the quartile range; circles indicate outliers out of the 1.5 times quartile range.

shortage of high quality food supply at any time of the breeding season.
Fig. (4). Growth of toe span (without claws) during chick development $(\mathrm{n}=150)$. For comparison adult values are given 
with females $(n=25)$ and males $(n=1)$ on the right side, , the red dashed line shows the mean value of adults. boxplot: horizontal line shows the median; the top and the bottom of the box show the $25^{\text {th }}$ and the $75^{\text {th }}$ percentiles; the vertical dashed lines ('whiskers') show either maximum value or 1.5 times the quartile range; circles indicate outliers out of the 1.5 times quartile range.

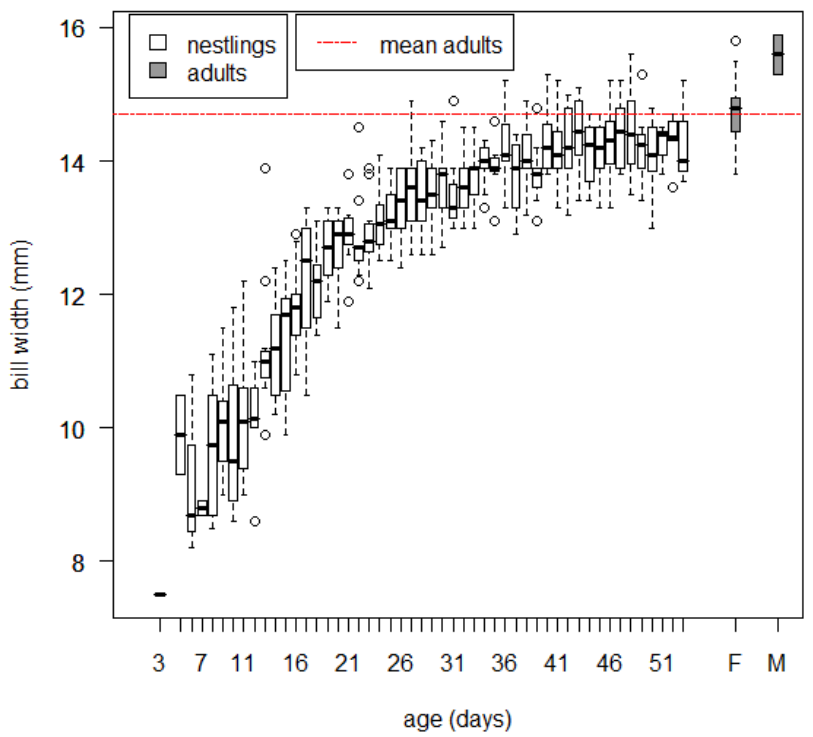

Fig. (4). Growth of bill width during chick development $(n=150)$. For comparison adult values are given with females $(F$, $n=25)$ and males $(\mathrm{M}, \mathrm{n}=2)$ on the right side, the red dashed line shows the mean value of adults. boxplot: horizontal line shows the median; the top and the bottom of the box show the $25^{\text {th }}$ and the $75^{\text {th }}$ percentiles; the vertical dashed lines ('whiskers') show either maximum value or 1.5 times the quartile range; circles indicate outliers out of the 1.5 times quartile range.

Table 2. ANOVA Test of Morphological Features between Female and Male Chicks. P-values and Significance Level Evaluate the Role of Sex Used as a Main Factor in Our Linear Mixed-effect Model. Stages are Divided by Changes in Growth Curves

\begin{tabular}{|c|c|c|c|c|c|c|c|}
\hline Character & Age (Days) & Females (Mean) & Males (Mean) & P-value & Stage & $\begin{array}{c}\text { Females Daily Change } \\
\text { Per Stage }\end{array}$ & $\begin{array}{c}\text { Males Daily Change Per } \\
\text { Stage }\end{array}$ \\
\hline \multirow[t]{3}{*}{ Body mass (g) } & 15 & 89.40 & 83.78 & $<0.001$ & $0-25$ days & 5.52 & 5.52 \\
\hline & 31 & 148.52 & 145.07 & $<0.001$ & 30-55 days & -1.78 & -1.44 \\
\hline & 50 & 114.64 & 118.05 & $<0.001$ & $30-55$ days & -1.78 & -1.42 \\
\hline Bill length (mm) & 50 & 19.64 & 19.85 & $<0.001$ & 31-55 days & 0.18 & 0.18 \\
\hline \multirow[t]{2}{*}{ Bill width (mm) } & 14 & 11.03 & 11.07 & $<0.001$ & $0-25$ days & 0.22 & 0.22 \\
\hline & 50 & 14.13 & 14.32 & $<0.001$ & 26-55 days & 0.04 & 0.04 \\
\hline $\begin{array}{l}\text { Tarsus length } \\
(\mathrm{mm})\end{array}$ & 14 & 16.95 & 16.26 & $<0.001$ & $0-23$ days & 0.39 & 0.39 \\
\hline \multirow[t]{3}{*}{ Toe span (mm) } & 14 & 37.13 & 36.88 & n.s. & $0-23$ days & 1.47 & 1.47 \\
\hline & 25 & 45.69 & 46.03 & n.s. & 24-55 days & 0.05 & 0.05 \\
\hline & 50 & 46.86 & 47.24 & n.s. & 24-55 days & 0.05 & 0.05 \\
\hline \multirow[t]{2}{*}{ Wing (cm) } & 10 & 2.36 & 2.31 & n.s. & $0-15$ days & 0.18 & 0.18 \\
\hline & 50 & 17.01 & 16.83 & $<0.001$ & $16-55$ days & 0.37 & 0.37 \\
\hline \multirow[t]{2}{*}{ Tail (cm) } & 30 & 4.46 & 4.25 & $<0.001$ & 18-55 days & 0.33 & 0.33 \\
\hline & 50 & 11.12 & 10.93 & $<0.001$ & 18-55 days & 0.33 & 0.33 \\
\hline
\end{tabular}




\section{Bill Growth}

Bill size of adult RNP males is larger than that of adult females (Fig. 3, 4) [12, 38]. Already during nestling development male chicks of all age stages have longer and broader bills than the female siblings (Table 2). The development of bill length is almost linear with time with a slow decrease in the growth rate towards the end of the nestling stage (Fig. 3). The average bill length of adult females $(22.5 \mathrm{~mm})$ is not reached during nestling stage, but young females attain $87 \%$ of the adult value by the age of $50 \mathrm{~d}$.

The development of bill width is initially linear with time but flattens out towards the end of the nestling stage (Fig. 4). The average bill width of adult females $(14.7 \mathrm{~mm})$ is nearly attained by the end of the nestling stage with $96 \%$ in $50 \mathrm{~d}$ old females (mean values compared).

\section{Tarsus and Toe Growth}

Tarsus and toe length do not show a sexual dimorphism in adult RNP (Fig. 5,6). Tarsus length is significantly longer in female chicks as compared to male chicks in all three growth stages (Table 2). Tarsus growth is fastest in early chick development until the age of $20 \mathrm{~d}$ (Fig. 6) and follows a logarithmic growth pattern. The average tarsus length of adults $(18.0 \mathrm{~mm})$ is reached, even exceeded during the early nestling stage, with female chicks of $50 \mathrm{~d}$ of age reaching $100 \%$ of the adult tarsus length.

The growth of toe span occurs during the first $20 \mathrm{~d}$ (Fig. 6). The average toe span of adults $(44.6 \mathrm{~mm})$ is reached during early nestling stage of about $18 \mathrm{~d}$ of age and then exceeds this value after day 25 in both sexes and among all hatching orders (Tables $\mathbf{1}, \mathbf{2}$ ).

\section{Wing Development}

In RNP the first feathers appeared at an age of c. $14 \mathrm{~d}$ (Fig. 1). Primaries, which contribute to the wing length, started growing from day 16 onwards. Wing growth is almost linear over the nestling stage with a slow decrease of growth rate towards the end (Fig. 7). The average wing length of adult females $(17.3 \mathrm{~cm})$ is nearly reached by the end of the nestling stage, with female chicks reaching 17.0 $\mathrm{cm}(98 \%)$ at day 50 as compared to $16.8 \mathrm{~cm}$ in males (Table 2).

\section{Tail Growth}

The development of tail feathers is quite linear, starting at an age of c. $18 \mathrm{~d}$ (Fig. 8). The average tail length of adults $(20.7 \mathrm{~cm})$ is not reached by the end of the nestling stage. Females attain $11.1 \mathrm{~cm}(54 \%)$ at day 50 and males $10.9 \mathrm{~cm}$ which apparently have longer tails as adults (Fig. 8). Tail length may be underestimated because tips sometimes were broken due to nesting behaviour and limited space in nest boxes.

\section{Influence of Hatching Order on Chick Development}

Depending on the hatching order body mass of young RNP differed significantly (Tab. 1). On day 15 first-hatched chicks had a weight of $79.4 \mathrm{~g}$ whereas it was $80.2 \mathrm{~g}$ in lasthatched chicks and $83.0 \mathrm{~g}$ in intermediate-hatched chicks.
The daily increase of body mass in the early nestling stage (0-25 d) is $5.6 \mathrm{~g} \mathrm{~d}^{-1}$ (Table $\mathbf{1}$; Fig. 9).

In the subsequent nestling phase (d 30-55, Fig. 10), firsthatched chicks attained a body mass of $144.6 \mathrm{~g}$ on d 31, lasthatched chicks of $139.9 \mathrm{~g}$ and intermediate chicks of $142.0 \mathrm{~g}$ (Table 1). Furthermore, intermediate-hatched chicks show significantly higher measurements in nearly all other characters, like bill length, bill width, tarsus, toe span, wing, and tail length than first- and last-hatched chicks (Table 1).

\section{Sex-dependent Nestling Development}

When 15 d old, female chicks weigh about 89.4 g, whereas males are $5.6 \mathrm{~g}$ lighter. The daily gain in weight is $5.5 \mathrm{~g}$ in both sexes in the early nestling stage (0-25 d). Differences between sexes are significant $(\mathrm{p}<0.001)$. In the subsequent nestling phase (30-55 d) body mass decreases in both sexes, but the slopes are significantly different $(\mathrm{p}<0.05)$. At an age of $31 \mathrm{~d}$, females weigh $148.5 \mathrm{~g}$ and males $145.1 \mathrm{~g}$. Females lose $1.7 \mathrm{~g} \mathrm{~d}^{-1}$, whereas males only lose $1.4 \mathrm{~g} \mathrm{~d}^{-1}$ (Table 2).

Adult RNP males have larger bills, wings and tails than females [7, 38]. Surprisingly our study shows, that female chicks are significantly heavier in the early nestling phase, which gives them an advance of $1-2 \mathrm{~d}$ as compared to male chicks. Furthermore, females show a significantly longer tarsus, wing and tail (Table 2). Bill length and width are the only characters in which male chicks outperform female chicks (Table 2) which agrees with the finding that adult RNP have bigger bills than females (s. above).

\section{Breeding Success and Mortality}

The average clutch size in 69 broods was $4.08 \pm 1.42$ eggs, with $61.3 \%$ of eggs hatching and $79.2 \%$ of all chicks surviving until fledging (3.5\% of chicks have been rescued, hand raised and released). Total mortality of 173 chicks in the nest was $17.3 \%$. After day 25, mortality of chicks was independent of hatching order.

\section{DISCUSSION}

Body mass data from this study were similar to those of the Asian P. k. borealis [7], and other RNP $(\mathrm{n}=292)$ breeding in Europe (UK) [35]. As compared to $141.7 \mathrm{~g}$ in Butler [35], birds in our study were heavier with $149.3 \mathrm{~g}$. However, our data are biased as they derived almost completely from adult females caught at the beginning of the breeding season. Females in the egg-production period weigh more than after egg-laying as they carry the developing eggs. The heaviest recorded bird in literature (180 g) was a female in egg-laying stage caught in Southern England in March [35: 184]. The maximum body mass of a nestling, which exceeded the weight of any of our adult RNP, recorded in this study was $175 \mathrm{~g}$; it came from a $31 \mathrm{~d}$ old female chick.

Normally, the body mass of bird nestlings does not exceed that of the adults. Exceptions are found in pelagic birds, swallows and swifts. These species have a long nestling stage, spend long times for foraging in flight, and nestlings may feed for themselves directly or soon after fledging. For these species a reduction of the overweight (produced as nes- 
tlings) before fledging is common [39]. In parrots, a weight reduction before fledging has been found in cockatoos like Cacatua tenuirostris [40], C. pastinator [41], Calyptorhynchus funereus [42], C. latirostris [43], and neotropical parrots like Myiopsitta monachus [44], Amazona viridigenalis [45], Rhynchopsitta sp. [46], or Burrowing Parrots [47].

The body mass in RNP peaked at day 31, about $20 \mathrm{~d}$ prior to fledging. The mean body mass reduction in RNP chicks accounted for $23 \%$ in females and $19 \%$ in males. Similar values have been reported for the Burrowing Parrot with a weight reduction of 23\% [48]. Burrowing Parrots had maximum body mass at an age of $38 \mathrm{~d}$, but chicks stay in the nest for $60 \mathrm{~d}$ [48]. Studies on other parrots, like cockatoos, Myiopsitta monachus, or Rhynchopsitta pachyrhyncha, show similar patterns [overview given in 48]. The pre-fledging weight peak of RNP occurs earlier than in Crimson Rosellas, in which the weight maximum was reached $10 \mathrm{~d}$ prior to

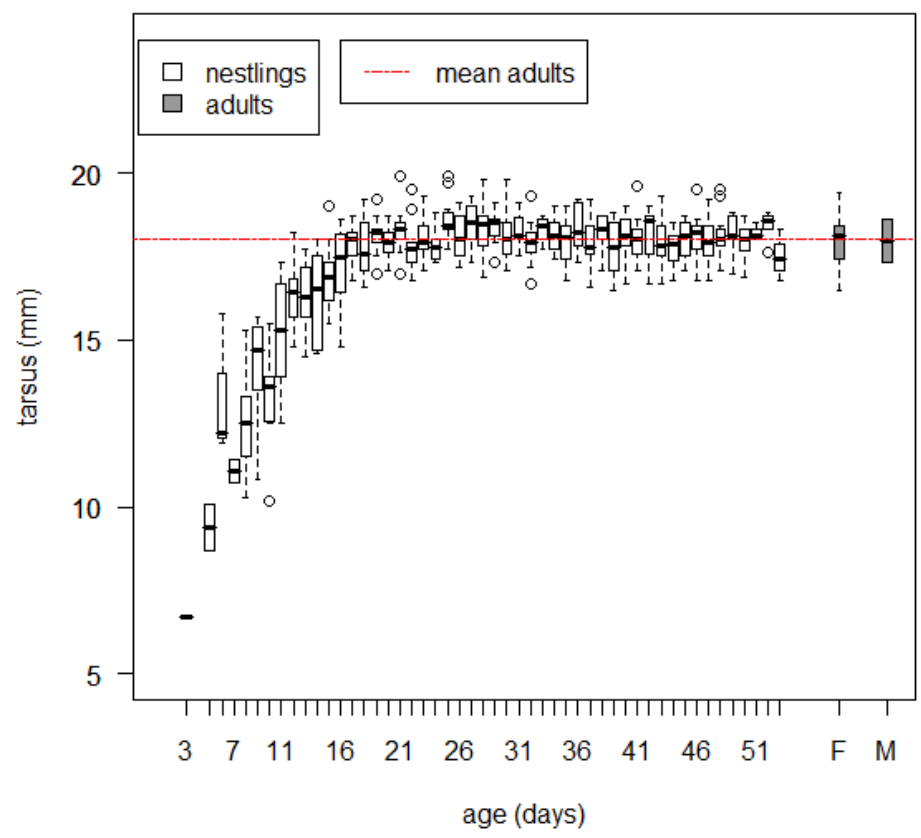

Fig. (5). Tarsus growth during chick development $(n=150)$. For comparison adult values are given with females (F, $n=25)$ and males (M, $\mathrm{n}=2$ ) on the right side, the red dashed line shows the mean value of adults. boxplot: horizontal line shows the median; the top and the bottom of the box show the $25^{\text {th }}$ and the $75^{\text {th }}$ percentiles; the vertical dashed lines ('whiskers') show either maximum value or 1.5 times the quartile range; circles indicate outliers out of the 1.5 times quartile range.

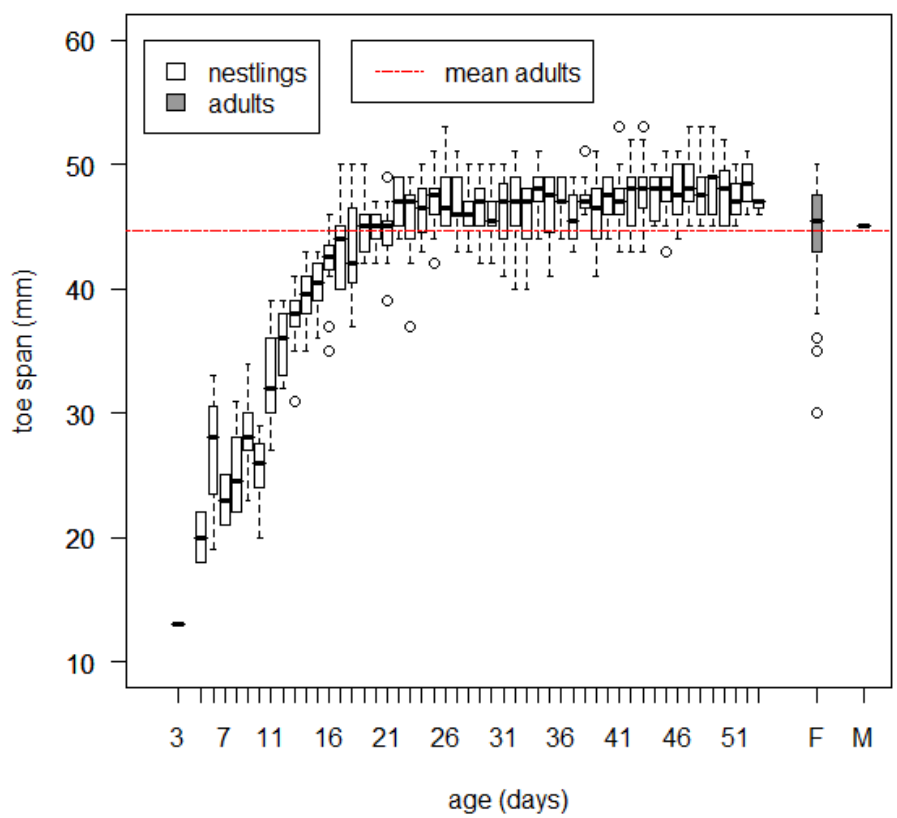

Fig. (6). Growth of toe span (without claws) during chick development $(\mathrm{n}=150)$. For comparison adult values are given with females ( $\mathrm{n}=25)$ and males $(\mathrm{n}=1)$ on the right side, the red dashed line shows the mean value of adults. boxplot: horizontal line shows the median; the top and the bottom of the box show the $25^{\text {th }}$ and the $75^{\text {th }}$ percentiles; the vertical dashed lines ('whiskers') show either maximum value or 1.5 times the quartile range; circles indicate outliers out of the 1.5 times quartile range. 


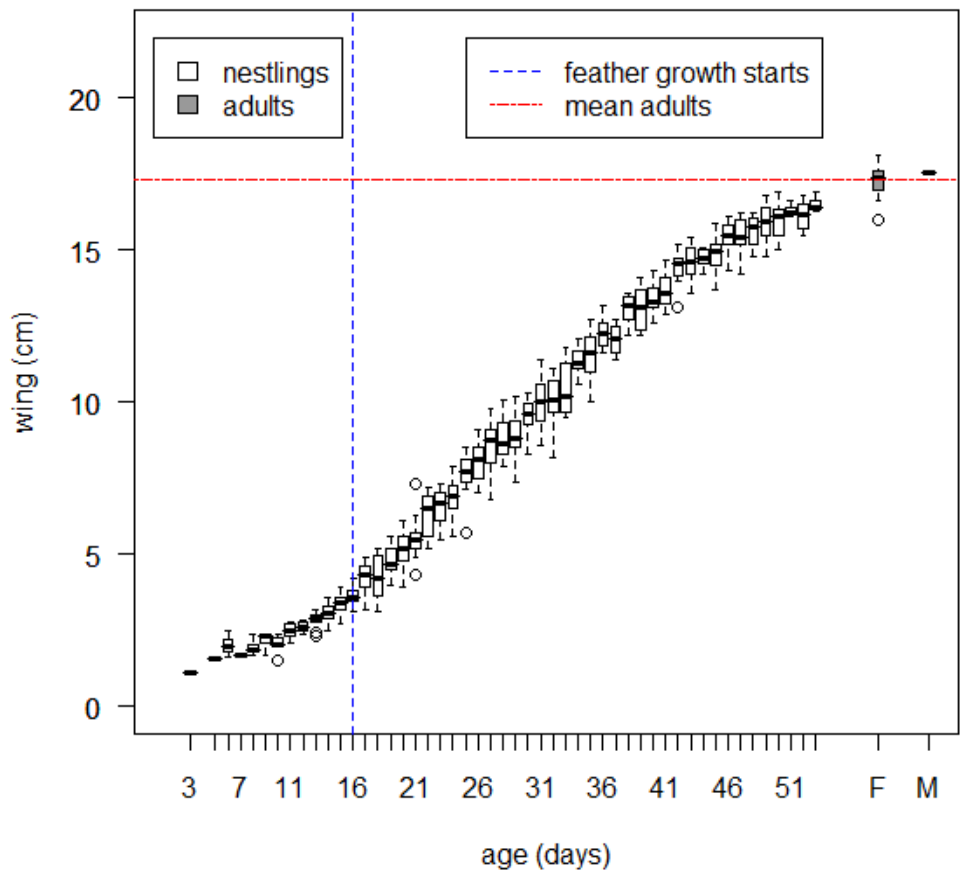

Fig. (7). Wing growth during chick development ( $n=150)$. For comparison adult values are given with females $(F, n=25)$ and males $(M, n=2)$ on the right side, , the red dashed line shows the mean value of adults. boxplot: horizontal line shows the median; the top and the bottom of the box show the $25^{\text {th }}$ and the $75^{\text {th }}$ percentiles; the vertical dashed lines ('whiskers') show either maximum value or 1.5 times the quartile range; circles indicate outliers out of the 1.5 times quartile range.

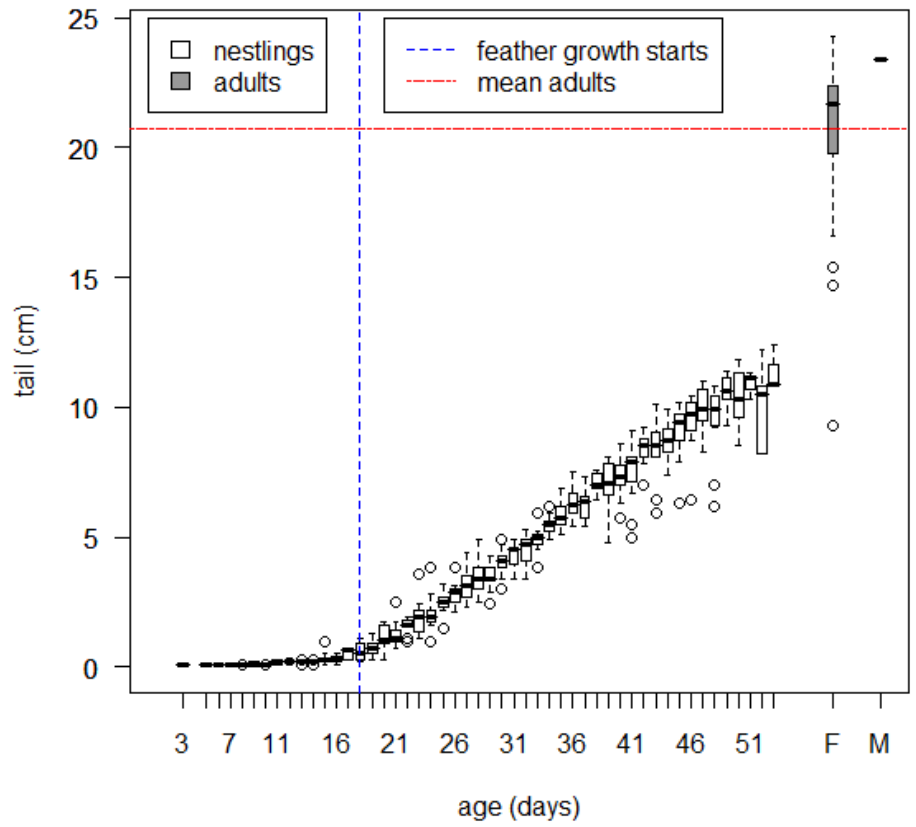

Fig. (8). Tail growth during chick development $(n=150)$. For comparison adult values are given with females $(F, n=25)$ and males $(M, n=1)$ on the right side, , the red dashed line shows the mean value of adults. boxplot: horizontal line shows the median; the top and the bottom of the box show the $25^{\text {th }}$ and the $75^{\text {th }}$ percentiles; the vertical dashed lines ('whiskers') show either maximum value or 1.5 times the quartile range; circles indicate outliers out of the 1.5 times quartile range.

fledging; but rosellas exhibit a shorter nestling stage of only $35 \mathrm{~d}[21,49]$.

Tarsus length is the only other morphometric character (beside the body mass) which decreases (about 2\% loss) at the end of the nestling stage. Young nestlings have a soft fleshy skin tissue covering their tarsus, which becomes dry and solid, sometimes even skinny in light-weight chicks during the late nestling phase. For $P$. $k$. borealis similar data have been published [12]. A comparable pattern in tarsus development has been seen in Burrowing Parrots in which prefledging chicks have a similar tarsus length as adult birds [38]. Krebs [21] used the tibia as a measure for the overall skeletal size. The linear tibial growth phase was very short, 


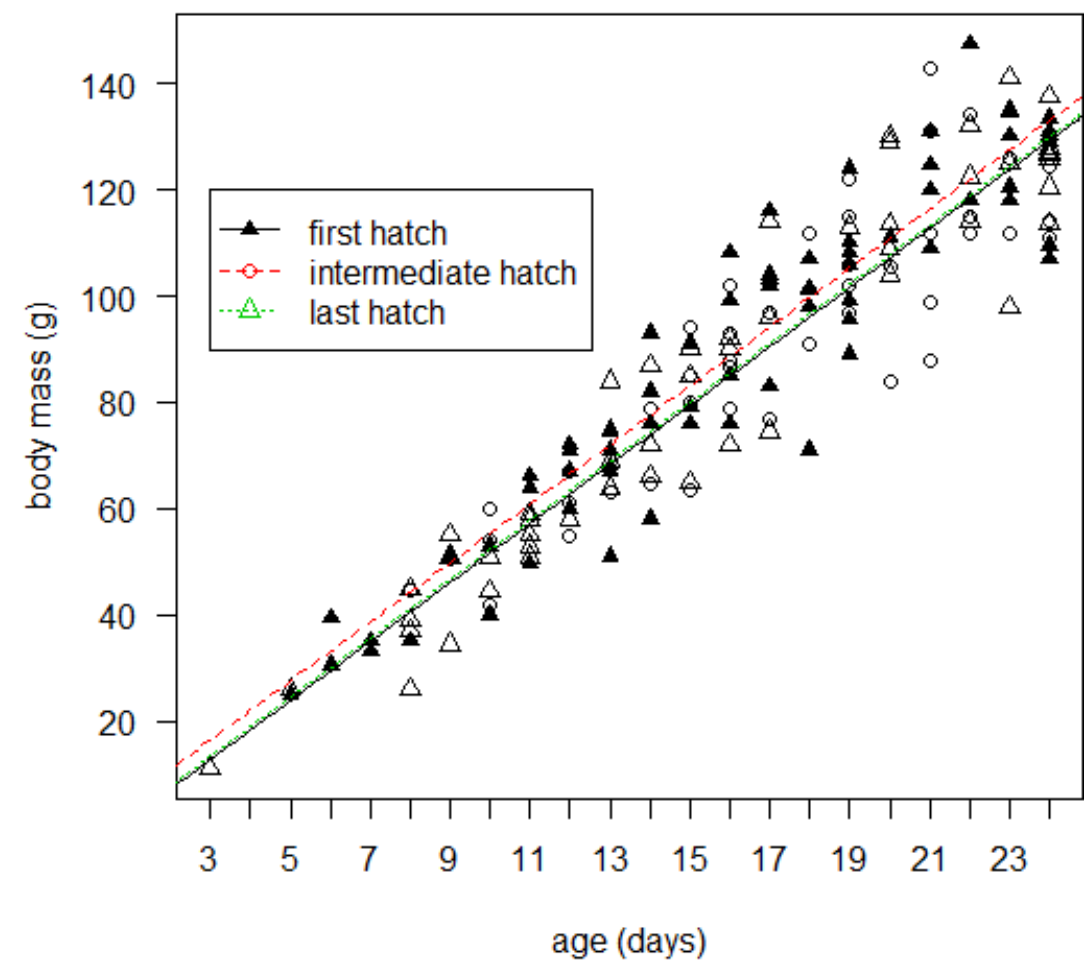

Fig. (9). Differences in body mass increase of in early chick development due to hatching order.

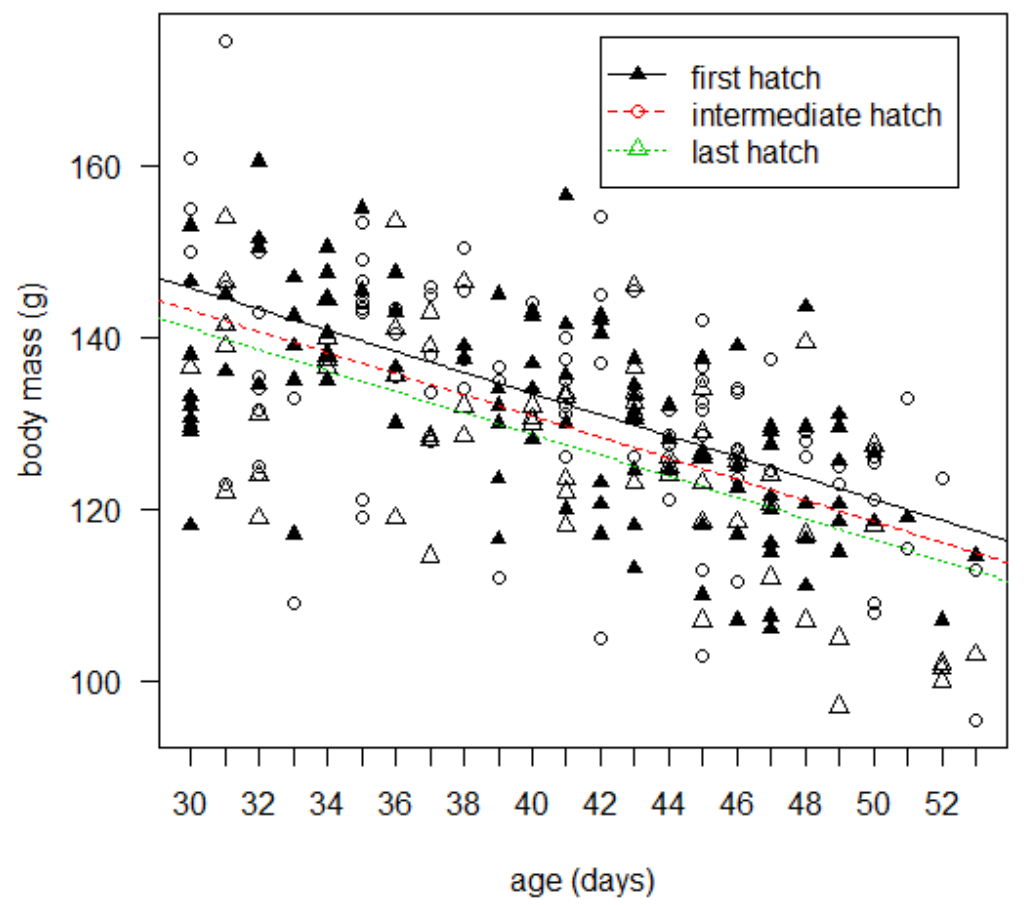

Fig. (10). Differences in body mass decrease in late chick development due to hatching order.

taking place only between 1 and $10 \mathrm{~d}$ in Platycercus elegans. This indicates that in parrots the development of skeletal structures is attained very quickly and basically before the start of feather growth (s. Fig. 1).

Males of nearly all investigated RNP subspecies except parvirostris have longer wings than females [12, 38]. Prefledglings of Burrowing Parrots reached 92\% of the adult wing length [40]. Therefore pre-fledging female chicks of
RNP which reach $98 \%$ of the adult length apparently have excellent fledging conditions. Even a chick at only $43 \mathrm{~d}$ of age, attaining $86 \%$ of the adult wing length, was well capable of flying (Braun and Wink, in prep.). The mean growth rate for wing length in RNP nestlings was $3.7 \mathrm{~mm} \mathrm{~d}^{-1}$, being $1.1 \mathrm{~mm} \mathrm{~d}^{-1}$ less than in Burrowing Parrots [48]. This finding is not surprising as adults of the latter species nearly twice as heavy as adult RNP. 
Tail length is dimorphic in RNP with males having longer tails in all subspecies [38]. In Burrowing Parrots tail growth started at an age of $25 \mathrm{~d}$ [40]. In RNP tail growth began at an age of $18 \mathrm{~d}$, resulting in a slightly faster development than in Burrowing Parrots. Fledglings of Burrowing Parrots attain $72 \%$ of the adult tail length without significant differences between sexes or hatching order. Our findings are different: RNP fledglings only reach $54 \%$ of the adult tail length. This may be due to the relatively longer tail in RNP as compared to Burrowing Parrots, which makes up to 59\% of the total body length as compared to $53 \%$ in Burrowing Parrots [max. values compared to body length in 50]. The average growth rate of tales in RNP was $3.4 \mathrm{~mm} \mathrm{~d}^{-1}$, being about $0.6 \mathrm{~mm} \mathrm{~d}^{-1}$ lower as compared to the nearly doublesized Burrowing Parrot.

As chicks of both sexes fledged at about $50 \mathrm{~d}$ of age, the literature value of seven weeks is quite adequate [50], whereas Wilson and Roselaar [7] give a shorter range of 40 to $50 \mathrm{~d}$. Benson et al. [51] mentioned the fledging age as spanning from 46 to $61 \mathrm{~d}$ for the African subspecies and $49 \mathrm{~d}$ for the Indian subspecies.

Masello and Quillfeldt [48] had proposed an allometric relationship of fledging age in relation to body mass for several parrot species. Burrowing Parrots stay $11 \mathrm{~d}$ longer in the nest than expected from the model. The authors concluded that the prolonged nestling stage did not pose an additional predation risk to the nestlings, but contributed to the magnitude of mass recession which was observed during their study. In RNP, fledging takes place $4 \mathrm{~d}$ after the expected date from allometric model of Masello and Quillfeldt.

Our finding that chick developmental traits are independent of clutch size and hatching date is surprising because environmental factors vary substantially during the breeding season. The hatching date of RNP extended over 10 calendar weeks ( $26^{\text {th }}$ of March to $29^{\text {th }}$ of May). The German spring season is characterized by an enormous change in food quality for RNP during flowering and fruiting time of 42 tree and shrub species (50\% of which were non-native species) [14]. From May to September, RNP live mainly on fruits (90\% of food items) [14], but use a high amount of buds, flowers, leaves, and shoots in preceding months [52]. RNP benefit from a high tree and shrub species diversity in urban areas with at least 85 recorded food plants in Germany with special focus on Acer spec., Aesculus hippocastanum, Populus spec., Quercus spec., Hedera helix, Carpinus betulus, Malus spec., and Prunus spec. [52].

In the mass gain phase, first-hatched chicks were lighter as compared to their younger siblings, and even lower than the last-hatched ones; the young that had hatched in the middle of the hatching order were the heaviest. In the mass recession phase, the results show another pattern: now the first-hatched chicks had an advantage as compared to their younger siblings. In the late nestling phase, parents feed less often (Braun \& Wink, in prep.) and food supply decreases for all siblings at the same time, but now the eldest chicks benefit from being closer to fledging as compared to the younger ones. Chicks of intermediate hatching rank obtained the best values not only in body mass but also in the other morphological characters, such as growth of tarsus, toe span, wing and tail (Table 1). The only character that differed from this pattern was bill development, as intermediate-hatched chicks show highest values both for bill length and width, except for the early development (5-30 d), when last-hatched chicks are having the highest growth rate in bill length (Table 1).

These data can be interpreted as a means to overcome hatching asynchrony and to synchronise fledging. In RNP, the chicks are dependent on their parents for about two weeks after fledging [53], so they have to move to the nearby feeding grounds. If chicks fail to fledge in time, they may starve, because the parents focus on the already fledged young and return less often to feed the remaining chicks in the nest (Braun and Wink in prep.). Our results thus agree with the hypothesis that RNP belong to those parrots which prefer feeding the younger chicks in order to synchronize fledging.

In contrast, in Burrowing Parrots first-hatched chicks produced the longest wing length and the last-hatched chicks the shortest one, whereas tail length was independent from hatching order [40]. For Crimson Rosellas [21] no significant differences in the linear growth rate of wing chord or other variables, neither in chicks of different sex nor of different hatching order, were found. In Green-rumped Parrotlets, parents of asynchronously hatched broods required significantly less energy than parents of artificially synchronized broods. Although the magnitude of peak energy demand was similar both in asynchronous and synchronous broods, the temporal duration of high energy demand was lower in asynchronous broods [54]. Experimentally synchronized broods in Greenrumped Parrotlets fledged as many or more young than asynchronous broods [55].

Mortality in RNP chicks was low and nestling mortality was not correlated with hatching order. Mortality in Burrowing Parrots tended to be higher in younger nestlings, but the survival rate between hatching and fledging was very high in this species (91\%) [40]. Although some nest boxes of our RNP were in reach of Red Squirrels (Sciurus vulgaris), a known nest predator of birds, the nest safety of the study population was very high; not even a single registered case of nest predation was recorded.

\section{CONCLUSION}

Most biometric variables exhibited similar patterns during RNP nestling development. Female RNP chicks showed a faster growth as compared to their male siblings and firsthatched chicks were smaller as compared to their younger siblings.

In parrots, hatching and fledging asynchrony is common. In seed-eating species an unsynchronized fledging may not be of disadvantage, like in the budgerigar, in which chicks may feed independently soon after fledging. In the predominantly fruit-eating RNP with a wide variety of food plants, fledglings are fed by their parents for some time after leaving the nest and have to learn the selection of food items. Remaining siblings in the nest are under pressure to fledge quickly because the parents will return less often to the nest. Weakness and mortality may be the result of a delayed ability to fledge. Our study indicates that RNP is a species in which 'fledging synchronization' is operational. 


\section{CONFLICT OF INTEREST}

The authors confirm that this article content has no conflicts of interest.

\section{ACKNOWLEDGEMENT}

We thank all persons who helped in measuring and sampling the birds, or in the lab, namely Mirjam Reinke, Hedi Sauer-Gürth, Detlev Franz, Jenny Richber, Roelant Jonker, Grace Innemee, Nina Strychalski, Andreas Bauer, Verian Beck, Stefanie Neumann, Karolin Späth, Claudia Heft, Kathrin Obernberger, Jessica Dietrich, Marcel Paulmann, Tabea Sinkovic, Kristin Führle, Sascha Günthner, Christine Jeckel, Severin Uebbing, Michael Preusch, Jörg Edelmann, Stefan Flörchinger, Doro Koch, Iris Heynen, Sonja Käßmann, Christoph Randler, Evelyn Fellhauer, Victoria Fellhauer, Luisa Menrath, Christina Czajka. For statistical analysis we thank Holger Schielzeth, Stefanie von Felten and especially Fränzi Korner-Nievergelt. For improving the manuscript we thank two anonymous reviewers and Nicole Ludwig.

The present study was carried out under permission of the regional council Karlsruhe.

\section{REFERENCES}

[1] Braun M. Population development of the Ring-necked Parakeet Psittacula krameri in the Rhine-Neckar Region (Germany: BadenWürttemberg, Rhineland-Palatinate, Hesse), 1962-2008, in the context of its distribution in Europe]. Vogelwelt 2009; 130.

[2] Lever C. Naturalised Birds of the World. London: T \& A D Poyser 2005.

[3] Sovon. Atlas van de Nederlands vogels. Arnhem: Schuyt 1987.

[4] Ali S, Ripley SD. Handbook of the Birds of India and Pakistan, together with those of Bangladesh, Nepal, Bhutan and Sri Lanka. Bombay, London: Oxford University Press 1969.

[5] Czajka C, Braun M, Wink M. Resource use of non-native Ringnecked Parakeets (Psittacula krameri) and native Starlings (Sturnus vulgaris) in Central Europe. Open Ornithol J 2011; 4: 17-22.

[6] Khan AK. Breeding habitats of the Rose-ringed Parakeet (Psittacula krameri) in the cultivations of central Punjab. Int $\mathrm{J}$ Agric Biol 2002; 4: 401-3.

[7] Wilson MG, Roselaar CS. Psittacula krameri Ring-necked Parakeet (Rose-ringed Parakeet). In: Cramp S, Ed. Handbook of the Birds of Europe, the Middle East and North Africa The Birds of the Western Palearctic. Oxford: Oxford University Press 1985; pp. 379-87.

[8] Shivanarayan N, Babu KS, Ali MH. Breeding biology of Roseringed Parakeets Psittacula krameri at Maruteru. Pavo 1981; 19: 92-6.

[9] Lamba BS. Nidification of some common Indian birds: 10. The Rose-ringed Parakeet, Psittacula krameri Scopoli. Proc Zool Soc Calcutta 1966; 19: 77-85.

[10] Ernst U. Afro-asiatische Sittiche in einer mitteleuropäischen Großstadt: Einnischung und Auswirkung auf die Vogelfauna. Cologne University 1995.

[11] Shwartz A, Strubbe D, Butler CJ, Matthysen E, Kark S. The effect of enemy-release and climate conditions on invasive birds: a regional test using the rose-ringed parakeet (Psittacula krameri) as a case study. Divers Distribut 2009; 15: 310-8.

[12] Roselaar CS, Wilson MG. Psittacula krameri. Ring-necked Parakeet (Rose-ringed Parakeet). In: Cramp S, Ed. Handbook of the birds of Europe, the Middle East, and North Africa The birds of the Western Palearctic. Oxford: Oxford University Press 1985; pp. 379-87.

[13] Pithon JA, Dytham C. Breeding performance of Ring-necked Parakeets Psittacula krameri in small introduced populations in southeast England. Bird Study 1999; 46: 342-7.
[14] Braun M. Alien species in urban habitats: ecology and niche expansion of Ring-necked Parakeets (Psittacula krameri Scopoli, 1769) in Heidelberg, Germany: Marburg Philipps-University 2004.

[15] Braun M. How does thermal insulation on buildings - as a result of EU climate protection - affect the breeding biology of tropical Ring-necked Parakeets (Psittacula krameri) in temperate Central Europe? Ornithol Jahresh Baden-Wurtt 2007; 23: 39-56.

[16] Budden AE, Beissinger SR. Against the odds? Nestling sex ratio variation in green-rumped parrotlets. Behav Ecol 2004; 15: 607-13.

[17] Krebs EA. Breeding biology of crimson rosellas (Platycercus elegans) on Black Mountain, Australian Capital Territory. Aust J Zool 1998; 46: 119-36.

[18] Robinet O, Salas M. Reproductive biology of the endangered Ouvea Parakeet Eunymphicus cornutus uvaeensis. Ibis 1999; 141: 660-9.

[19] Masello JF, Quillfeldt P. Chick growth and breeding success of the Burrowing Parrot. Condor 2002; 104: 574-86.

[20] Krebs EA. Last but not least: Nestling growth and survival in asynchronously hatching crimson rosellas. J Anim Ecol 1999; 68: 266-81.

[21] Krebs EA. Last but not least nestling growth and survival in asynchronously hatching crimson rosellas. J Anim Ecol 1999; 57: 155-70.

[22] Collar NJ. Psittacidae (Parrots). In: del Hoyo J, Elliott A, Pargatal J, Eds. Handbook of the birds of the world: Sandgrouse to cuckoos. Barcelona: Lynx 1997; pp 280-477.

[23] Soma M, Saito DS, Hasegawa T, Okanoya K. Sex-specific maternal effect on egg mass, laying order, and sibling competition in the Bengalese finch (Lonchura striata var. domestica). Behav Ecol Sociobiol 2007; 61: 1695-705.

[24] Weimerskirch H, Barbraud C, Lys P. Sex differences in parental investment and chick growth in Wandering Albatrosses: Fitness consequences. Ecology 2000; 81: 309-18.

[25] Muller W, Groothuis TGG, Dijkstra C. Consequences of sexspecific growth on sibling competition in black-headed gulls: a sexually-size dimorphic species with scramble competition. J Ornithol 2007; 148: 495-502.

[26] Hayward LS, Richardson JB, Grogan MN, Wingfield JC. Sex differences in the organizational effects of corticosterone in the egg yolk of quail. Gen Comp Endocrinol 2006; 146: 144-8.

[27] Grossmann R, Muehlbauer E, Reiprich K, Josza R. Expression of the growth hormone gene during embryonic and posthatch development of the chicken. J Anim Breed Genet 1996; 113: 255-9.

[28] Forshaw JM. Parrots of the World - an identification guide. Princeton and Oxford: Princeton University Press 2006.

[29] Braun M. How does thermal insulation on buildings - as a result of EU climate protection - affect the breeding biology of tropical Ring-necked Parakeets (Psittacula krameri) in temperate Central Europe? Ornithol Jahreshefte Baden-Württemberg Neulubheim: OGBM 2007; vol. 23: pp. 39-56.

[30] Wink M. Advances in DNA studies of diurnal and nocturnal raptors. In: Chancellor RD, Meyburg B-U, Eds. Raptors at risk Alaska:WWGBP/Hancock House 2000. p. 831-44.

[31] Arctander P. Comparative studies of avian DNA by restriction fragment polymorphism analysis1. J Ornithol1988; 129: 205-16.

[32] Sambrook J, Fritsch EF, Maniatis T. Molecular cloning: a Laboratory Manual. $2^{\text {nd }}$ ed. New York: Cold Spring Harbor Laboratory Press 1989.

[33] Kahn NW, John JS, Quinn TW. Chromosome-specific intron-size differences in the avian CHD gene provide an efficient method for sex identification in birds. Auk 1998; 115: 1074-8.

[34] Proctor NS, Lynch PJ. Manual of ornithology: avian structure and function. Ann Arbor, Michigan: Edwards Brothers Inc. 1993.

[35] Butler C. Population biology of the introduced Rose-ringed Parakeet Psittacula krameri in the UK. Thesis Oxford: Oxford University 2003.

[36] McKain D. A Novice's Bird Breed J 2012 [updated 2012; cited, Accessed: 2012 Nov. 15]; Available from: http://www.netpets.org/birds/reference/mckain/dayindex.html.

[37] R_Development_Core_Team. R: a language and environment for statistical computing. Vienna, Austria: R Foundation for Statistical Computing 2008.

[38] Forshaw JM. Parrots of the world. Willoughby: Weldon Publishing 1978.

[39] Ricklefs JE. Patterns of growth in birds. Ibis 1968; 110: 419-51. 
[40] Saunders DA. Breeding of the Long-billed Corella at Coomallo Creek, W. A. Emu 1977; 77: 223-7.

[41] Smith GH. Breeding ecology of the western Long-billed Corella, Cacatua pastinator pastinator. Wildl Res 1991; 18: 91-110.

[42] Saunders DA. The breeding behaviour and biology of the shortbilled form of the Whitetailed Black Cockatoo Calyptorhynchus funereus. Ibis 1982; 124: 422-55.

[43] Saunders DA. Breeding season, nesting success and nestling growth in Carnaby's Cockatoo, Calyptorhyncus funereus latirostris, over 16 years at Coomallo Creek, and a method for assessing the viability of populations in other areas. Aust Wildl Res 1986; 13: 261-73.

[44] Navarro JL, Martella MB, Bucher EH. Breeding season and productivity of Monk Parakeets in Cordoba, Argentina. Wilson Bull 1992; 104: 413-24.

[45] Enkerlin-Hoeflich EC. Comparative ecology and reproductive biology of three species of Amazona parrots in northeastern Mexico. Texas: A \& M University 1995.

[46] Enkerlin-Hoeflich EC, Macías Caballero C, Monterrubio Rico TC, et al. Status, distribución, ecología y conservación de las cotorras serranas (Rhynchopsitta terrisi y Rhynchopsitta pachyrhyncha) en el norte de Mexico $4^{\mathrm{a}}$ parte. . In: México C, México DF, Eds. Comisión Nacional para el uso y conocimiento de la biodiversidad 1999.
[47] Lubjuhn T, Sramkova A, Masello JF, Quillfeldt P, Epplen JT. Truly hypervariable DNA fingerprints due to exceptionally high mutation rates. Electrophoresis 2002; 23: 517-9.

[48] Masello JF, Quillfeldt P. Chick growth and breeding success of the burrowing parrot. Condor 2002; 104: 574-86.

[49] Krebs EA. Begging and food distribution in crimson rosella (Platycercus elegans) broods: why don’t hungry chicks beg more? Behav Ecol Sociobiol 2001; 50: 20-30.

[50] Arndt T, Ed. Lexicon of Parrots. Bretten: Arndt-Verlag 1996.

[51] Benson CW, Benson FM, Stuart SN, Fry CH. Psittacula krameri (Scopoli), Rose-ringed Parakeet; Ring-necked Parakeet. Perruche á collier. In: Fry CH, Keith S, Urban EK, Eds. The Birds of Africa. London. San Diego: Academic Press 1988.

[52] Franz D, Krause T. Biologie und Verbreitung des Halsbandsittichs in Deutschland - Teil 2. Papageien 2003; 6: 209-13.

[53] Ernst U. Afro-asiatische Sittiche in einer mitteleuropäischen Großstadt: Einnischung und Auswirkung auf die Vogelfauna. Jahrbuch für Papageienkunde 1995; 1: 23- 114.

[54] Siegel RB, Weathers WW, Beissinger SR. Hatching asynchrony reduces the duration, not the magnitude, of peak load in breeding green-rumped parrotlets (Forpus passerinus). Behav Ecol Sociobiol 1999; 45: 444-50.

[55] Stoleson SH, Beissinger SR. Hatching asynchrony, brood reduction, and food limitation in a Neotropical parrot. Ecol Monogr 1997; 67: 131-54.

(C) Braun and Wink; Licensee Bentham Open.

This is an open access article licensed under the terms of the Creative Commons Attribution Non-Commercial License (http://creativecommons.org/licenses/by-nc/3.0/) which permits unrestricted, non-commercial use, distribution and reproduction in any medium, provided the work is properly cited. 